\title{
Elisa Donzelli, Come lenta cometa. Traduzione e amicizia poetica nel carteggio tra Sereni e Char
}

\section{Fabio Scotto}

\section{(2) OpenEdition}

1 Journals

\section{Edizione digitale}

URL: http://journals.openedition.org/studifrancesi/6433

DOI: ERREUR PDO dans /localdata/www-bin/Core/Core/Db/Db.class.php L.34 : SQLSTATE[HYO00]

[2006] MySQL server has gone away

ISSN: 2421-5856

\section{Editore}

Rosenberg \& Sellier

\section{Edizione cartacea}

Data di pubblicazione: 1 novembre 2010

Paginazione: 590

ISSN: 0039-2944

\section{Notizia bibliografica digitale}

Fabio Scotto, «Elisa Donzelli, Come lenta cometa. Traduzione e amicizia poetica nel carteggio tra Sereni e Char», Studi Francesi [Online], 162 (LIV | III) | 2010, online dal 30 novembre 2015, consultato il 08 janvier 2021. URL: http://journals.openedition.org/studifrancesi/6433 ; DOI: https://doi.org/ERREUR PDO dans /localdata/www-bin/Core/Core/Db/Db.class.php L.34 : SQLSTATE[HY000] [2006] MySQL server has gone away

Questo documento è stato generato automaticamente il 8 janvier 2021.

\section{(c)}

Studi Francesi è distribuita con Licenza Creative Commons Attribuzione - Non commerciale - Non opere derivate 4.0 Internazionale. 


\title{
Elisa Donzelli, Come lenta cometa. Traduzione e amicizia poetica nel carteggio tra Sereni e Char
}

\author{
Fabio Scotto
}

\section{NOTIZIA}

ELISA DONZELLI, Come lenta cometa. Traduzione e amicizia poetica nel carteggio tra Sereni e Char, Torino, Nino Aragno, 2009, pp. 168.

1 Nato a Luino, luogo suggestivo e segreto sulla sponda lombarda del Lago Maggiore che con Piero Chiara ha contribuito a rendere celebre, Vittorio Sereni (1913-1983) è stato, oltre che uno dei maggiori poeti italiani del secondo Novecento, anche un importante traduttore, di Corneille e di W. C. Williams, tra gli altri, ma soprattutto di René Char (1907-1988), al quale ha dedicato molte fervide energie. Quindi meritoria appare ora l'opera di Elisa Donzelli, la quale ritraccia la storia dei rapporti umani e letterari fra questi due grandi poeti affidandosi in particolare al loro ricco carteggio, cui ha attinto dall'Archivio Sereni della Biblioteca Comunale di Luino.

2 La monografia, che segue una progressione diacronica, è articolata in tre parti. Nella prima (1960-1968. Il giorno nel segno d'Ipnos, pp. 19-62), l'A. ricostruisce le dinamiche della inizialmente non facile ricezione della poesia di Char in Italia, in un quadro che vede fra i protagonisti, con Sereni, Giorgio Caproni, Giorgio Bassani e Piero Bigongiari, e l'inizio della loro amicizia, caratterizzata dapprima da una sorta di timore reverenziale da parte di Sereni nei confronti dell'autore dei Feuillets d'Hypnos, poi da una crescente, reciproca confidenza e fiducia, come attesta il mutato tono delle clausole epistolari del carteggio, che si svolge anche da parte del poeta luinese quasi esclusivamente in francese. A legarli sarà dapprima soprattutto l'esperienza della Resistenza, e il fatto che, come afferma Sereni in un'intervista del 1975, «i Feuillets d'Hypnos erano l'altra faccia rispetto al mio Diario d'Algeria» (p. 56, nota 88). 
3 Nella seconda parte (1968-1982. Il notturno Sopramonte, pp.65-133) è dato conto in particolare della gestazione di Ritorno Sopramonte, l'ampia antologia chariana a cura di Sereni che gli varrà nel 1976 il Premio Monselice per la traduzione; periodo di frequenti viaggi di lavoro e di convivialità familiare nel Vaucluse avignonese presso la Sorga di petrarchesca memoria dove il poeta francese vive. Qui Elisa Donzelli mette in evidenza, alla luce del pensiero di Michel Collot, la poetica del paesaggio nella prospettiva dettata dal punto di vista di un soggetto tipica di Char (p.73) che, secondo Mengaldo, agisce come elemento decisivo di una necessaria trasformazione della traduzione in poesia tramite l'imitazione del paesaggio stesso, traduzione che segue «una linea filante e assomiglia a una stella cometa che chiede spazio vitale per la propria scia luminosa» (p. 94). Imitativa dello spirito del luogo piuttosto che del lavoro del significante, la traduzione di Sereni ricorre all'inversione sintattica, alla trasformazione del parallelismo in chiasmo, all'uso verbale del participio presente e alla variatio, come attestano utili esempi a p. 105, nel segno di una vera riscrittura d'autore riconosciuta da Caproni e dallo stesso Char, il quale, nel novembre 1973, si dice fiero «d'être devenu grâce à Vittorio Sereni, un poète italien, un vrai poète d'amont» (p. 113). La generosità di Sereni starà anche nel non chiedere mai niente in cambio; il progetto di Char d'inserire e far tradurre Sereni in un'antologia francese non andrà a buon fine, per motivi anche imputabili forse alla spigolosità e imprevedibilità umorale del carattere del poeta francese. Nondimeno, la terza parte (Appunti per una lettera imperfetta, pp.135-164) rivela l'importanza esercitata dal tradotto nell'esperienza poetica del traduttore, in particolare nella sezione Traducevo Char della raccolta sereniana Stella variabile (1982), ipertestualmente assai tributaria del testo chariano, nel segno di una per la critica controversa «attrazione mimetica» (p.146), se ogni lettera/lettura, come ogni poesia, è innanzitutto «domanda di ascolto» (p. 164). 